\title{
A randomized study using functional respiratory imaging to characterize bronchodilator effects of glycopyrrolate/formoterol fumarate delivered by a metered dose inhaler using co-suspension delivery technology in patients with COPD
}

This article was published in the following Dove Press journal: International Journal of COPD

\author{
Wilfried De Backer' \\ Jan De Backer ${ }^{2}$ \\ Wim Vos ${ }^{3}$ \\ Ilse Verlinden ${ }^{3}$ \\ Cedric Van Holsbeke ${ }^{3}$ \\ Johan Clukers' \\ Bita Hajian' \\ Shahid Siddiqui ${ }^{4}$ \\ Martin Jenkins ${ }^{5}$ \\ Colin Reisner ${ }^{4,6}$ \\ Ubaldo J Martin ${ }^{4}$ \\ 'Department of Respiratory \\ Medicine, University of Antwerp, \\ Antwerp, Belgium; ${ }^{2}$ FLUIDDA, \\ Los Angeles, CA, USA; ${ }^{3}$ FLUIDDA, \\ Kontich, Belgium; ${ }^{4}$ AstraZeneca, \\ Gaithersburg, MD, USA; ${ }^{5}$ AstraZeneca, \\ Cambridge, UK; ${ }^{6}$ Pearl - A member of \\ the AstraZeneca Group, Morristown, \\ NJ, USA
}

Correspondence: Wilfried De Backer Department of Respiratory Medicine, University Hospital Antwerp, Universiteitsplein I, 2610 Wilrijk, Antwerp, BE 877160 706, Belgium Tel +32038809978

Email wilfried.debacker@uantwerpen.be
Background: Functional respiratory imaging (FRI) uses high-resolution computed tomography (HRCT) scans to assess changes in airway volume and resistance.

Patients and methods: In this randomized, double-blind, 2-week, crossover, Phase IIIB study, patients with moderate-to-severe COPD received twice-daily glycopyrrolate/formoterol fumarate delivered by a metered dose inhaler (GFF MDI, 18/9.6 $\mu \mathrm{g}$ ) and placebo MDI, formulated using innovative co-suspension delivery technology. Co-primary endpoints included the following: specific image-based airway volume (siVaw) and specific image-based airway resistance (siRaw) at Day 15, measured using FRI. Secondary and other endpoints included the following: change from baseline in post-dose forced expiratory volume in 1 second $\left(\mathrm{FEV}_{1}\right)$ and inspiratory capacity (IC; spirometry) and ratio to baseline in post-dose functional residual capacity (FRC) and residual volume (RV; body plethysmography).

Results: Twenty patients (46-78 years of age) were randomized and treated; of whom 19 completed the study. GFF MDI treatment increased siVaw by $75 \%$ and reduced siRaw by $71 \%$ vs placebo MDI (both $P<0.0001$ ). Image-based airway volume (iVaw) and image-based airway resistance (iRaw), without adjusting for lobe volume, demonstrated corresponding findings to the co-primary endpoint, as lobe volumes did not change with either treatment. Approximately $48 \%$ of the delivered dose of glycopyrronium and formoterol fumarate was estimated to be deposited in the lungs. Compared with placebo, GFF MDI treatment improved post-dose FEV and IC ( $443 \mathrm{~mL}$ and $454 \mathrm{~mL}$, respectively; both $P<0.001)$ and reduced FRC and RV $(13 \%$ and $22 \%$, respectively; both $P<0.0001$ ). There were no significant safety findings.

Conclusion: GFF MDI demonstrated significant, clinically meaningful benefits on FRI-based airway volume and resistance in patients with moderate-to-severe COPD. Benefits were associated with improvements in $\mathrm{FEV}_{1}$, IC, and hyperinflation.

Clinical trial registration: ClinicalTrials.gov: NCT02643082.

Keywords: GFF MDI, airway volume, airway resistance, inspiratory capacity, hyperinflation, LAMA/LABA

\section{Introduction}

Functional respiratory imaging (FRI), a post-processing technology, utilizes multislice high-resolution computed tomography (HRCT) scans and computational fluid dynamics to quantify anatomic and functional information in the respiratory system. ${ }^{1}$ 
FRI is considered a more sensitive method of investigating pharmacologically induced changes in the lungs than classical lung function tests. ${ }^{1-3}$ This image-based method opens up the possibility of providing a comprehensive assessment of airway tree changes both centrally and distally ${ }^{1,2}$ and has been used to detect regional changes in the $3 \mathrm{D}$ airway geometry in patients with COPD following bronchodilator treatment and to provide insights into the physiological effects of bronchodilators. ${ }^{1-3}$ FRI can generate functional data about airflow and drug deposition throughout the lobes of the lung. Previous FRI studies have assessed local and/or whole lung changes in airway volume and resistance in various settings, including after non-invasive or intrapulmonary percussive ventilation in patients with COPD; after surgical lung resection in patients with lung cancer; after receiving inhaled corticosteroid/long-acting $\beta_{2}$-agonist (ICS/LABA) fixed-dose combination (FDC) treatment in patients with asthma; and after receiving treatment with short-acting bronchodilators, roflumilast plus ICS/long-acting muscarinic antagonist (LAMA)/LABA, mucolytics, or ICS/LABA FDCs in patients with COPD. ${ }^{1-10}$

Glycopyrrolate/formoterol fumarate delivered by a metered dose inhaler (GFF MDI) is a LAMA/LABA bronchodilator FDC comprising glycopyrrolate/formoterol fumarate (GFF) delivered via a metered dose inhaler (MDI) and formulated using co-suspension delivery technology. ${ }^{11}$ In patients with moderate-to-very severe COPD, twicedaily GFF MDI 18/9.6 $\mu \mathrm{g}$ (equivalent to glycopyrronium/ formoterol fumarate dihydrate $14.4 / 10 \mu \mathrm{g}$ ) improved lung function and reduced hyperinflation, as demonstrated by improvements in inspiratory capacity (IC). ${ }^{12-14}$

This study uses FRI to further characterize the physiological effects of GFF MDI in patients with COPD, in addition to more traditional techniques such as spirometry and plethysmography. FRI is able to assess changes in volume and resistance in the third to the eighth bronchi generations, which allows for more precise evaluation of the anatomic areas in which GFF MDI exerts its activity than traditional techniques. The primary objective of this study was to assess, for the first time, the effect of 2 weeks of GFF MDI $18 / 9.6 \mu \mathrm{g}$ treatment compared with placebo MDI on specific image-based airway volume (siVaw) and specific imagebased airway resistance (siRaw) using FRI in patients with moderate-to-severe COPD (NCT02643082).

\section{Patients and methods}

\section{Study design and treatment}

Figure 1 shows the patient flow for this randomized, doubleblind, two-treatment, two-period, crossover, 2-week dosing, Phase IIIB study that was conducted at a single site in

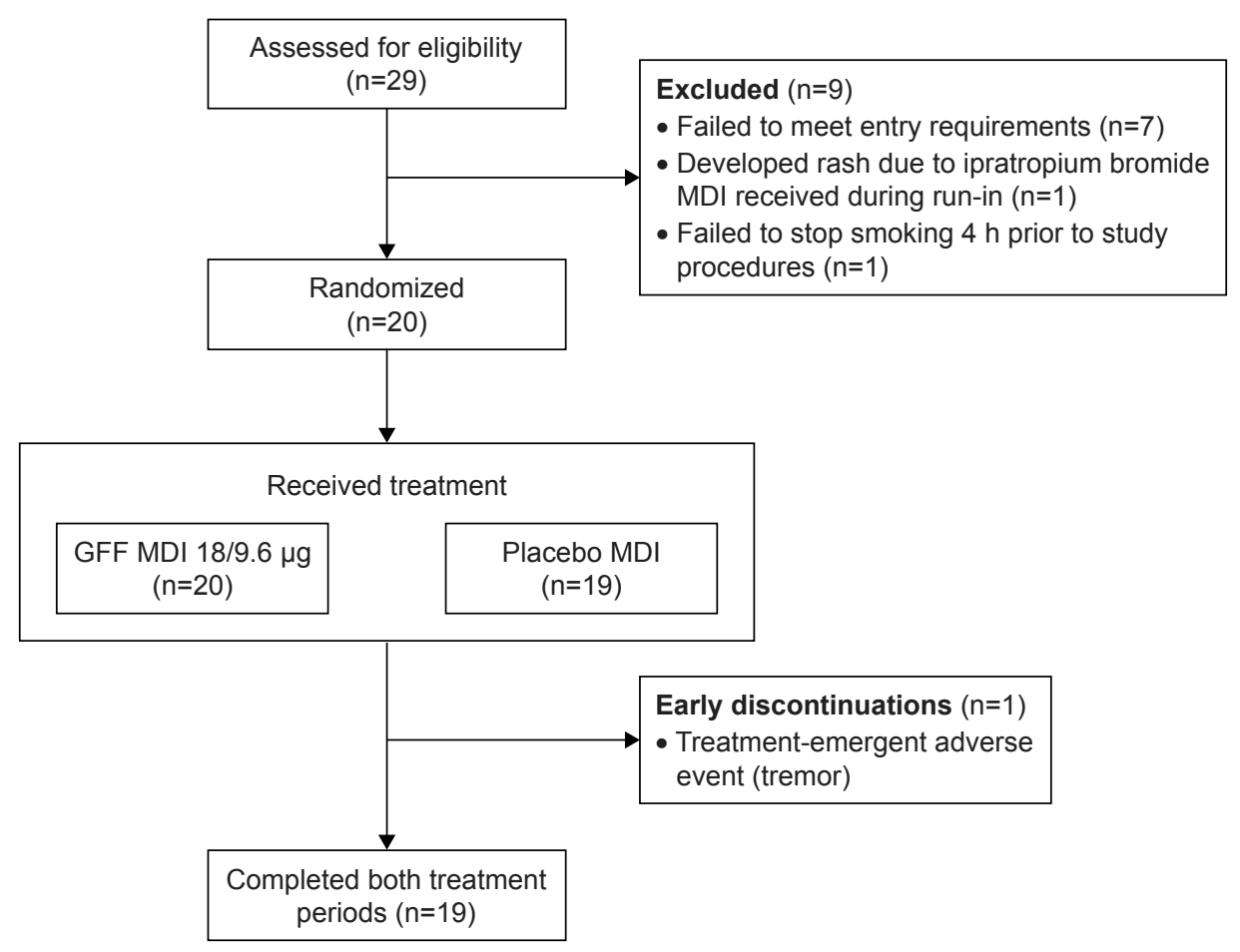

Figure I Patient disposition diagram.

Abbreviations: GFF, glycopyrrolate/formoterol fumarate; h, hours; MDI, metered dose inhaler. 


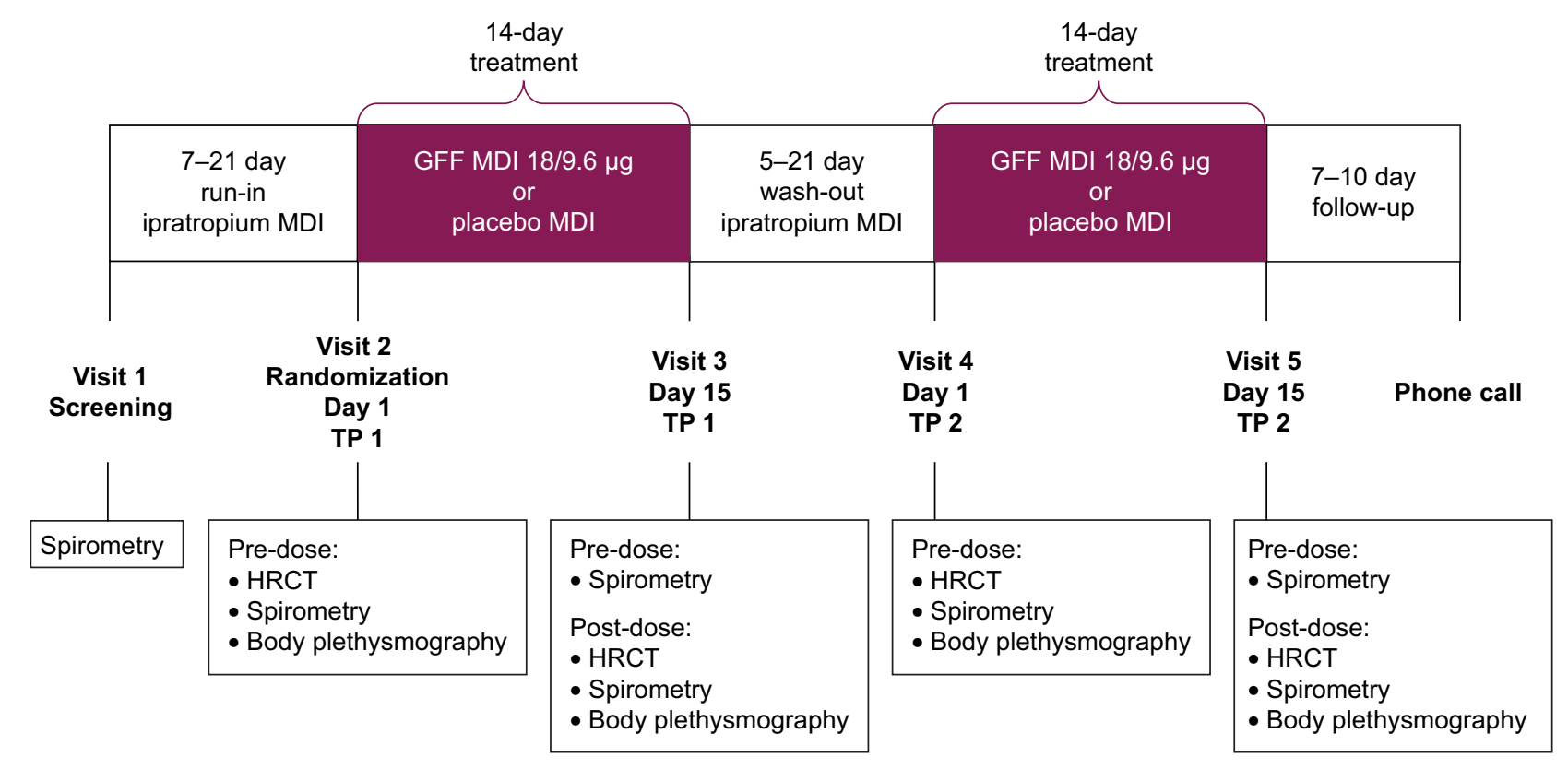

Figure 2 Study design.

Abbreviations: GFF, glycopyrrolate/formoterol fumarate; TP, treatment period; MDI, metered dose inhaler; HRCT, high-resolution computed tomography.

Belgium between January 11, 2016, and December 14, 2016. Patients received GFF MDI 18/9.6 $\mu \mathrm{g}$ twice daily and placebo MDI twice daily, delivered using innovative co-suspension delivery technology (Figure 2).

LAMAs, LABAs, LAMA/LABA FDCs, short-acting $\beta_{2}$-agonists, short-acting muscarinic antagonists, short-acting $\beta_{2}$-agonists/short-acting muscarinic antagonists, oral $\beta$-agonists, theophylline ( $>400 \mathrm{mg} /$ day), ICS/LABA FDCs, and leukotriene antagonists were discontinued prior to randomization and were not permitted throughout the study. Patients received sponsorprovided ipratropium bromide MDI (Atrovent ${ }^{\circledR}$ hydrofluoroalkane [Boehringer Ingelheim, Ingelheim am Rhein, Germany]) up to four times daily during the 7-21-day run-in and the 5-21day wash-out periods, and albuterol sulfate MDI (Ventolin ${ }^{\circledR}$ hydrofluoroalkane [GlaxoSmithKline plc, Brentford, London, UK]), for rescue use as needed throughout the study. Patients were permitted to receive maintenance ICS and/or roflumilast if they had been on a stable dose prior to enrolling in the study.

\section{Ethics approval and informed consent}

All patients provided written informed consent prior to any study-specific procedures. The study protocol was approved by the Universitair Ziekenhuis Antwerpen Ethics Committee (Wilrijkstraat 10, Edegem, Antwerp, Belgium 2650; approval number $15 / 44 / 465)$, and the study was performed in accordance with the Declaration of Helsinki and Good Clinical Practice Guidelines, applicable regulatory requirements, and the AstraZeneca policy on Bioethics.

\section{Patient population}

Patients were 40-80 years of age, with an established clinical history of moderate-to-severe COPD at screening (as defined by the European Respiratory Society and American Thoracic Society), ${ }^{15}$ with a pre-bronchodilator forced expiratory volume in 1 second $\left(\mathrm{FEV}_{1}\right) /$ forced vital capacity $(\mathrm{FVC})$ ratio of $<0.7$ and a post-bronchodilator $\mathrm{FEV}_{1}>30 \%$ and $<80 \%$ of predicted normal. Patients had a smoking history of $\geq 10$ pack-years and were willing to remain at the study center to complete all assessments. Exclusion criteria are included as Supplementary materials.

\section{Efficacy assessments}

Co-primary endpoints were siVaw and siRaw, relative to the lobar volume, at Day 15 (assessed using FRI). Secondary FRI endpoints included image-based airway volume (iVaw) and image-based airway resistance (iRaw) without adjustment for lobar volume at Day 15, and other FRI endpoints included image-based lobe volume (iVlobe) at total lung capacity (TLC) at Day 15 and mass of deposited particles at TLC. The secondary spirometry endpoint was change from baseline in post-dose $\mathrm{FEV}_{1}$, and other spirometry endpoints included change from baseline in IC and FVC, all at Day 15. The body plethysmography secondary endpoint was ratio to baseline in post-dose functional respiratory capacity (FRC), and other body plethysmography endpoints were residual volume (RV), TLC, airway resistance, specific airway resistance, and specific airway conductance, all ratio to baseline at Day 15 . 
FRI was performed on the distal airways as described in the study by Hajian et al. ${ }^{16}$ Details are included in Supplementary materials. Analysis of mass of deposited particles was performed as previously described in the study by De Backer et al. ${ }^{17}$

Spirometry assessments were performed at screening, 60 minutes and 30 minutes pre-dose on Days 1 and 15 and between 1 hour and 2.5 hours post-dose (after HRCT) on Day 15, in accordance with American Thoracic Society criteria. $^{18}$

Body plethysmography was performed 30 minutes predose on Day 1 and between 1 hour and 2.5 hours post-dose (after spirometry) on Day 15.

\section{Safety}

The safety assessments included physical examinations, vital sign measurements, electrocardiograms, and clinical laboratory tests. Adverse events (AEs) were monitored throughout the study.

\section{Statistical analyses}

The intent-to-treat population included all patients who were randomized and was used to conduct the efficacy analyses in all patients with evaluable post-baseline data. The safety population included all patients who were randomized and received at least one dose of study drug.

A sample size of 20 patients was selected using a sample size calculation ( $90 \%$ power and a significance level of 0.05 ) based upon a previous FRI study. ${ }^{1}$ Seven patients were required to assess iVaw, assuming a difference of $1 \mathrm{~mL}$ and an SD of within-patient differences of $0.6 \mathrm{~mL}$. Seventeen patients were needed to detect changes in iRaw. ${ }^{1}$

Functional data including siVaw and siRaw are presented as an average across all lobes of the lung. The Day 15 value for each FRI parameter in each period was analyzed using a linear mixed-effects model, with fixed effects for period, treatment, lobe, and treatment-by-lobe interaction. Data were logarithmically transformed prior to analysis. A multilevel model was used to incorporate the repeated measurements from the lobes for each patient. For the primary efficacy endpoints, Hochberg's step-up procedure was used as multiplicity adjustment for Type I error control. For spirometry and plethysmography endpoints, patient-average baselines were used based upon the mean of all available pre-dose assessments on Day 1 of both treatment periods (TPs). Pearson correlation coefficients were estimated to determine the association between FRI parameters and traditional spirometry and plethysmography assessments, in terms of change from baseline to Day 15. Due to the regional character of
FRI parameters, the log of the ratio of geometric mean values across all lobes of the lung was taken for these analyses.

\section{Results \\ Study population}

Twenty patients were randomized and received treatment. Nineteen (95\%) completed both TPs (Figure 1). One patient withdrew from the study while receiving GFF MDI treatment before the post-dose assessment and did not receive placebo MDI treatment. This patient had no post-randomization efficacy data and was therefore not included in efficacy analyses. Patients were 46-78 years of age, with an average post-bronchodilator $\mathrm{FEV}_{1}$ at screening of $60.1 \%$ of predicted normal. The demographics and baseline characteristics are summarized in Table 1, and details on prior COPD-related medications are shown in Table S1.

\section{FRI}

Treatment with GFF MDI resulted in a $75 \%$ increase in airway volume vs placebo MDI (siVaw; $P<0.0001$; Figure 3 ). These increases were seen consistently in all lobes, ranging from $66 \%$ to $88 \%$ within individual lobes, with the lower lobes showing numerically greater improvement in siVaw vs placebo MDI ( $85 \%-88 \%$ increase) compared with the middle and upper lobes $(66 \%-69 \%$ increase). Airway resistance (as measured by siRaw) was reduced by $71 \%$ following treatment with GFF MDI vs placebo MDI $(P<0.0001$; Figure 4). These reductions

Table I Demographics and baseline characteristics (safety/ intent-to-treat population)

\begin{tabular}{|c|c|}
\hline Parameters & Total $(\mathbf{N}=\mathbf{2 0})^{\mathrm{a}}$ \\
\hline Age (years), mean (SD); min-max & $64.8(8.7) ; 46-78$ \\
\hline Male, $\mathrm{n}(\%)$ & $15(75)$ \\
\hline Body mass index $\left(\mathrm{kg} / \mathrm{m}^{2}\right)$, mean $(\mathrm{SD})$ & $26.3(3.1)$ \\
\hline Moderate/severe COPD, n (\%) & $17(85) / 3(15)$ \\
\hline Duration of COPD (years), mean (SD); min-max & $6 . I(4.5) ; 0.2-15.6$ \\
\hline Number of pack-years smoked, ${ }^{b}$ mean (SD) & $51.3(4 I .4)$ \\
\hline $\begin{array}{l}\text { Pre-bronchodilator FEV, at screening (\%), } \\
\text { mean predicted (SD) }\end{array}$ & $53.9(11.4)$ \\
\hline $\begin{array}{l}\text { Post-bronchodilator FEV, at screening (\%), } \\
\text { mean predicted (SD) }\end{array}$ & $60.1(11.4)$ \\
\hline $\begin{array}{l}\text { Pre-bronchodilator FEV, at screening (L), } \\
\text { mean (SD) }\end{array}$ & $\mathrm{I} .63(0.5 \mathrm{I})$ \\
\hline $\begin{array}{l}\text { Post-bronchodilator FEV, at screening (L), } \\
\text { mean (SD) }\end{array}$ & $1.82(0.56)$ \\
\hline Pre-dose $\mathrm{FEV}$, at baseline $(\mathrm{L})$, mean $(\mathrm{SD})^{\mathrm{c}}$ & $1.59(0.56)$ \\
\hline
\end{tabular}

Notes: ${ }^{\text {OOnly }} 19$ patients were included in the efficacy analyses, as one patient withdrew early (due to a treatment-emergent adverse event of tremor) prior to any post-dose high-resolution computed tomography scans being performed. 'Number of pack-years smoked $=($ number of cigarettes per day/20) $\times$ number of years smoked. 'Baseline was defined as the mean of available pre-dose values from both treatment periods.

Abbreviations: $\mathrm{FEV}_{1}$, forced expiratory volume in I second; max, maximum; min, minimum. 

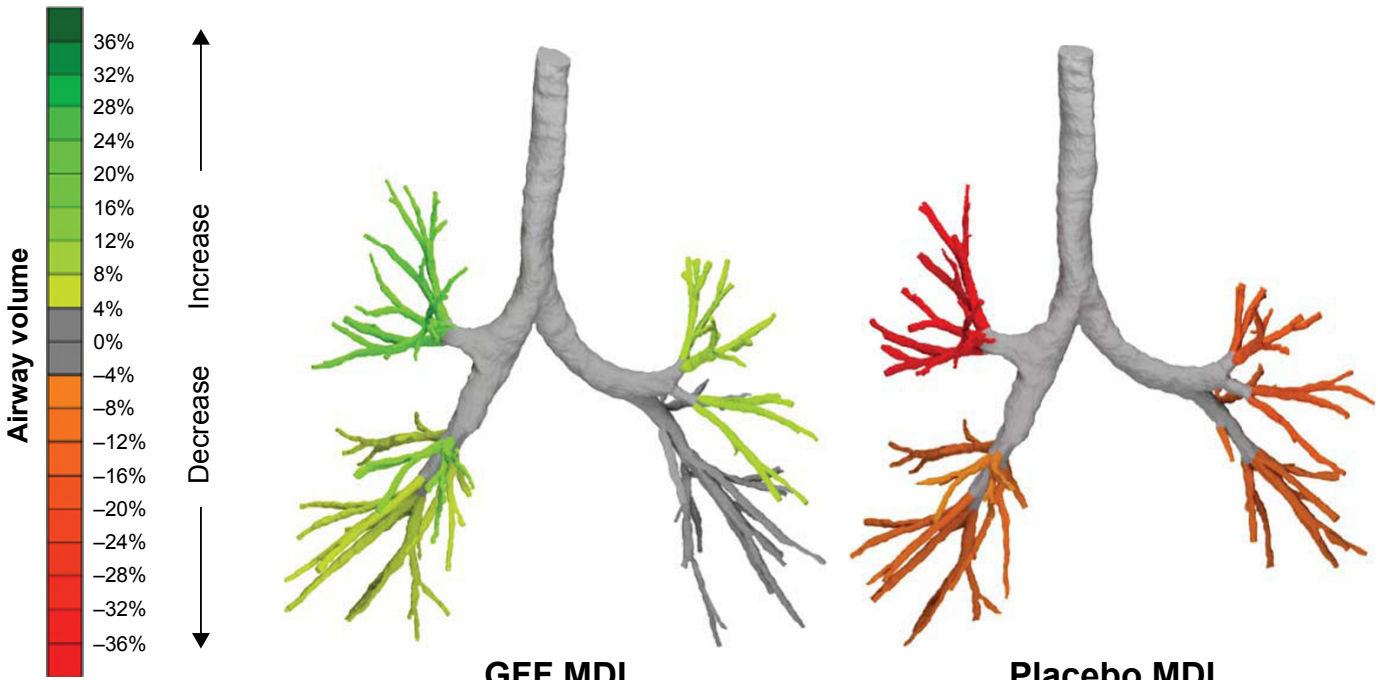

GFF MDI

Placebo MDI

\begin{tabular}{|c|c|c|c|c|}
\hline & GFF MDI (n=20) & Placebo MDI (n=19) & $\begin{array}{l}\text { LSM ratio of GFF MDI } \\
\text { versus placebo MDI }\end{array}$ & $P$-value \\
\hline No of patients/no of lobes & $19 / 92$ & $19 / 92$ & & \\
\hline Geometric LSM & 1.79 & 1.02 & 1.75 & $<0.0001$ \\
\hline$(95 \% \mathrm{Cl})$ & $(1.48-2.16)$ & $(0.85-1.24)$ & $(1.65-1.86)$ & \\
\hline
\end{tabular}

Figure 3 Functional respiratory imaging co-primary endpoint: siVaw at TLC on Day I5 (mL/L; intent-to-treat population).

Note: Images from one representative patient.

Abbreviations: GFF, glycopyrrolate/formoterol fumarate; LSM, least squares mean; MDI, metered dose inhaler; siVaw, specific image-based airway volume; TLC, total lung capacity.
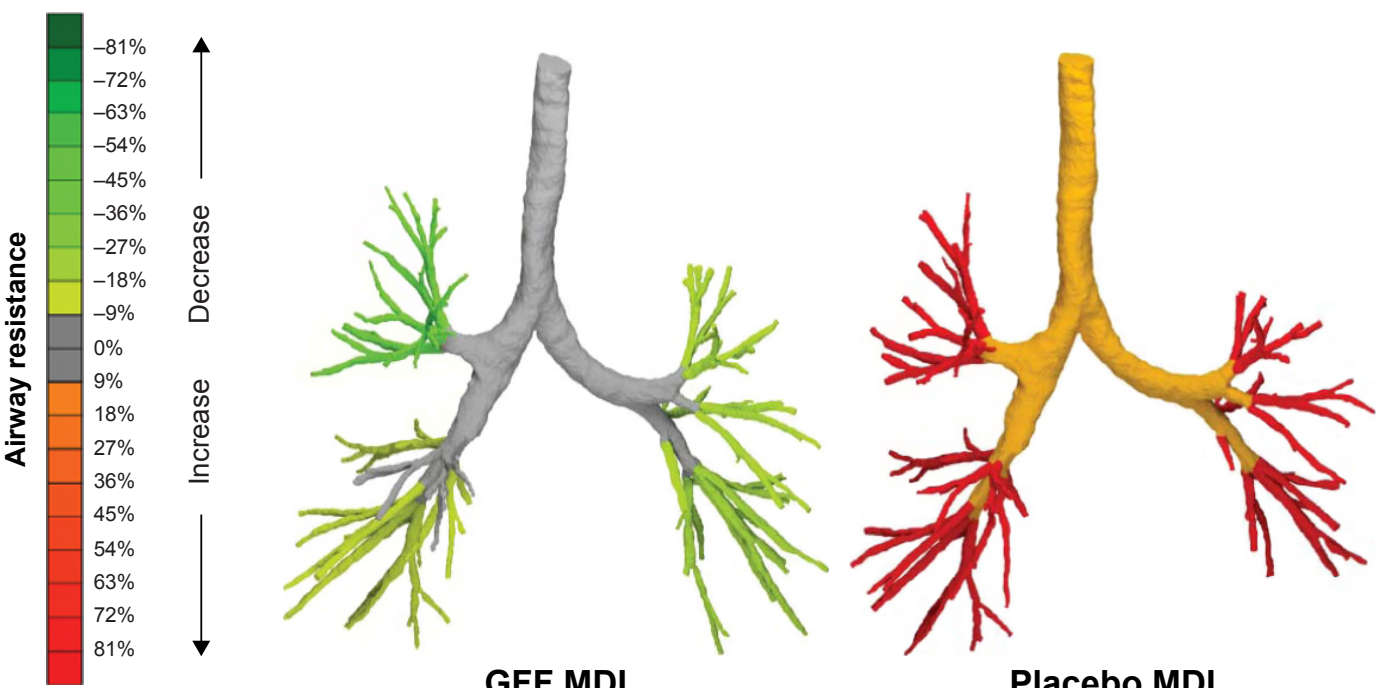

GFF MDI

Placebo MDI

\begin{tabular}{lllll}
\hline & GFF MDI $(\mathbf{n = 2 0})$ & Placebo MDI $(\mathbf{n = 1 9 )}$ & $\begin{array}{l}\text { LSM ratio of GFF MDI } \\
\text { vs placebo MDI }\end{array}$ & $P$-value \\
\hline No of patients/no of lobes & $19 / 92$ & $19 / 92$ & & $<0.0001$ \\
Geometric LSM & 0.09 & 0.30 & 0.29 & \\
$(95 \% \mathrm{Cl})$ & $(0.07-0.11)$ & $(0.23-0.40)$ & $(0.25-0.33)$ & \\
\hline
\end{tabular}

Figure 4 Functional respiratory imaging co-primary endpoint: siRaw at TLC on Day I5 (kPa.s; intent-to-treat population).

Note: Images from one representative patient.

Abbreviations: GFF, glycopyrrolate/formoterol fumarate; LSM, least squares mean; MDI, metered dose inhaler; siRaw, specific image-based airway resistance; TLC, total lung capacity. 
were also seen consistently in all lobes, ranging from $65 \%$ to $77 \%$ within individual lobes. Corresponding effects were seen in iVaw (79\% increase; $P<0.0001)$ and iRaw (71\% decrease; $P<0.0001)$, as there was no significant difference between treatments in change from baseline in iVlobe at TLC (least squares mean [LSM] ratio: $1.01 ; P=0.2902$ ).

For the mass of deposited particles simulation, $48.6 \%$ of the delivered glycopyrronium and $47.9 \%$ of the delivered formoterol fumarate were estimated to reach the lobes.

\section{Spirometry}

Treatment with GFF MDI led to an improvement vs placebo MDI on Day 15 in LSM change from baseline in post-dose $\mathrm{FEV}_{1}(443 \mathrm{~mL} ; P<0.0001)$, IC (454 mL; $\left.P=0.0006\right)$, and $\mathrm{FVC}\left(589 \mathrm{~mL} ; P<0.0001\right.$; Figure 5). Increase in $\mathrm{FEV}_{1}$ from baseline to Day 15 was strongly correlated with improvements in both siVaw $\left(R^{2}=0.71, P<0.001\right.$; Figure 6A) and siRaw $\left(R^{2}=0.75, P<0.001\right.$; Figure 6B).

\section{Body plethysmography}

GFF MDI treatment led to significantly reduced post-dose FRC and RV vs placebo MDI (geometric LSM ratios: 0.87 and 0.78 , respectively; both $P<0.0001$; Figure 7 ). There was a small decrease of $3 \%$ in TLC for GFF MDI vs placebo MDI (geometric LSM ratio: 0.97; $P=0.0110$; Figure 7). Improvements were also seen in airway resistance, specific airway resistance, and specific airway conductance (geometric LSM ratios: $0.48,0.43$, and 2.32 , respectively; all $P<0.0001$ ). The change in specific airway conductance from baseline to Day 15 was strongly correlated with the changes from baseline in both siVaw $\left(R^{2}=0.74, P<0.001\right.$; Figure S1A) and siRaw $\left(R^{2}=0.71, P<0.001\right.$; Figure $\left.\mathrm{S} 1 \mathrm{~B}\right)$.

\section{Safety}

Overall, 15 patients reported $\geq 1$ treatment-emergent $\mathrm{AE}$ (TEAE): 12 patients experienced a TEAE during the GFF MDI treatment period and eight patients experienced a TEAE during the placebo MDI treatment period. The most commonly observed AEs are listed in Table 2. Two serious TEAEs occurred: one acute myocardial infarction during treatment with GFF MDI and one acute coronary syndrome following treatment with placebo. Both were assessed by the investigator as possibly being related to the study drug. One patient discontinued the study due to a TEAE (severe tremor) that was considered by the investigator to be definitely related to the study drug. This patient had received 2 days of GFF MDI treatment when the event started and discontinued treatment 5 days later. The patient recovered 2 days after discontinuation.

There were no deaths during the study.

\section{Discussion}

In this Phase IIIB study using FRI to assess the effects of GFF MDI in patients with moderate-to-severe COPD, GFF MDI 18/9.6 $\mu \mathrm{g}$ increased specific airway volume by $75 \%$ and reduced specific airway resistance by $71 \%$, compared with placebo MDI. The FRI-observed changes occurred distally, between the third and eighth bronchi generations, and

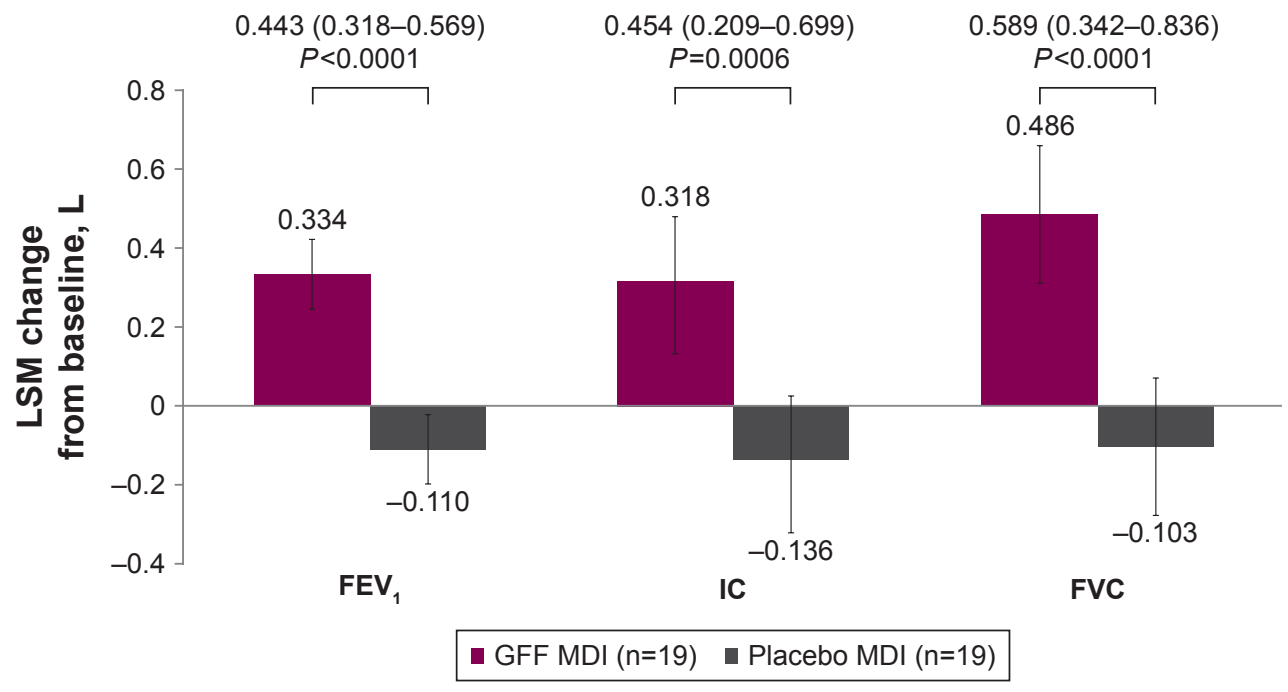

Figure 5 Spirometry endpoints on Day 15: change from baseline in post-dose FEV , IC, and FVC (intent-to-treat population).

Note: Error bars and parentheses represent $95 \% \mathrm{Cls.}$

Abbreviations: $\mathrm{FEV}_{1}$, forced expiratory volume in I second; FVC, forced vital capacity; GFF, glycopyrrolate/formoterol fumarate; IC, inspiratory capacity; LSM, least squares mean; MDI, metered dose inhaler. 

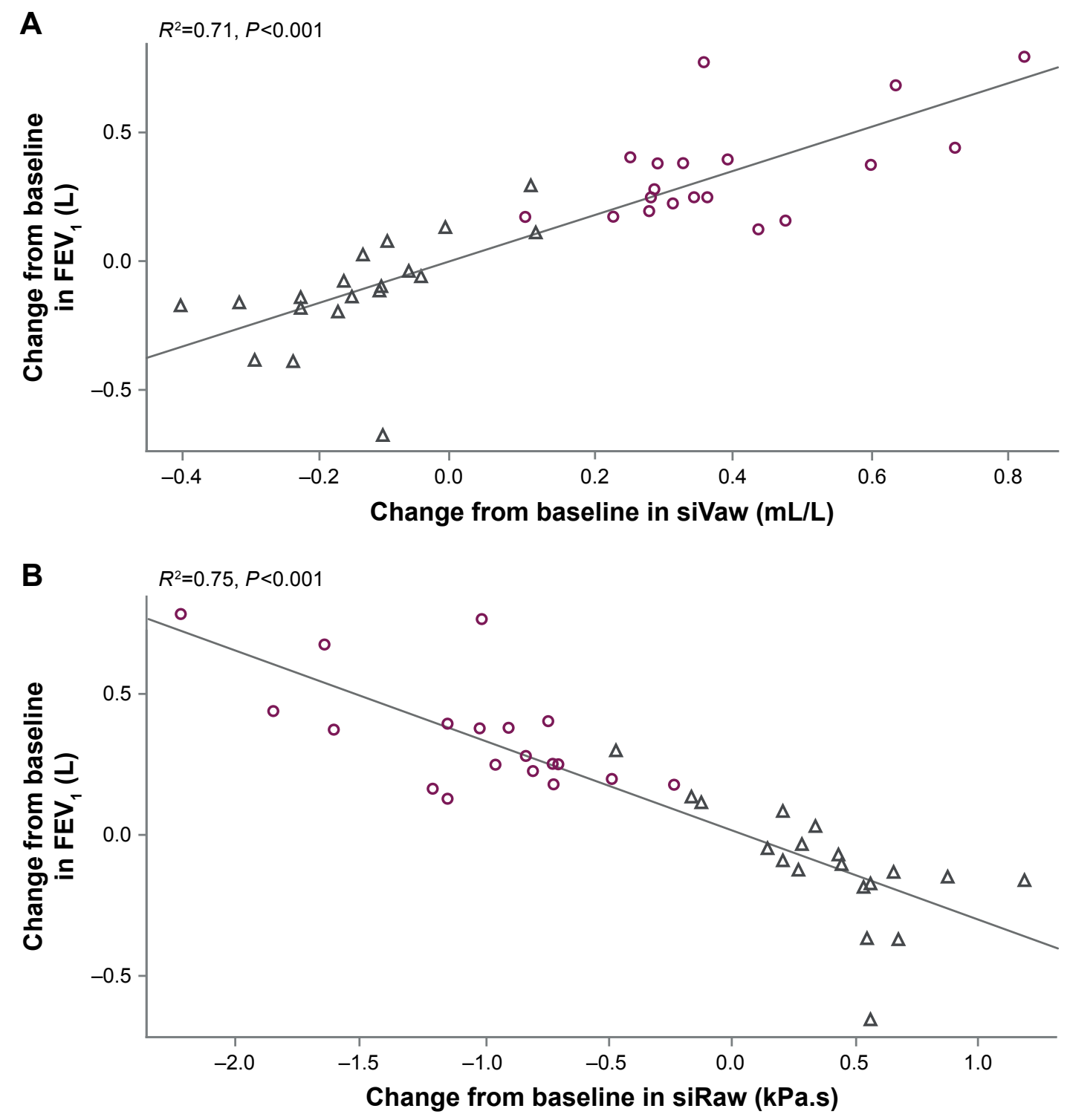

○ GFF MDI 18/9.6 $\mu \mathrm{g}(\mathrm{n}=19) \quad \Delta$ Placebo MDI $(\mathrm{n}=19)$

Figure 6 Scatter plot comparison of change from baseline in siVaw (A) and siRaw (B) with change from baseline in FEV at Day I5.

Abbreviations: $\mathrm{FEV}_{1}$, forced expiratory volume in I second; GFF, glycopyrrolate/formoterol fumarate; MDI, metered dose inhaler; siRaw, specific image-based airway resistance; siVaw, specific image-based airway volume.

were associated with clinically meaningful improvements in post-dose $\mathrm{FEV}_{1}$ and IC. ${ }^{19}$ This indicates an important reduction in hyperinflation after treatment with GFF MDI. ${ }^{20-23}$ Furthermore, the improvements in lung function with GFF MDI vs placebo MDI seen in this study were consistently reflected across other FRI, spirometry, and body plethysmography evaluations. Improvements in specific airway volume and resistance were highly correlated with the magnitude of improvement in $\mathrm{FEV}_{1}$, suggesting that these FRI parameters mirror the findings of spirometric testing, with the added benefit of indicating the regional distribution of the effects on lung function.
The FRI showed homogeneous increases in airway volume and decreases in airway resistance across all lobes of the lung. Although no direct head-to-head comparisons have been made, the homogeneous improvements in airway volume and resistance in this study appeared to be more uniform than previous FRI studies of other COPD inhalation therapies, including ICS/LABA combinations. ${ }^{1-3}$ This increase in volume and decrease in resistance across all lobes of the lung led to increased airflow throughout all regions of the lung and may ultimately avoid ventilation/perfusion mismatch due to selective bronchodilation in poorly perfused areas of the 


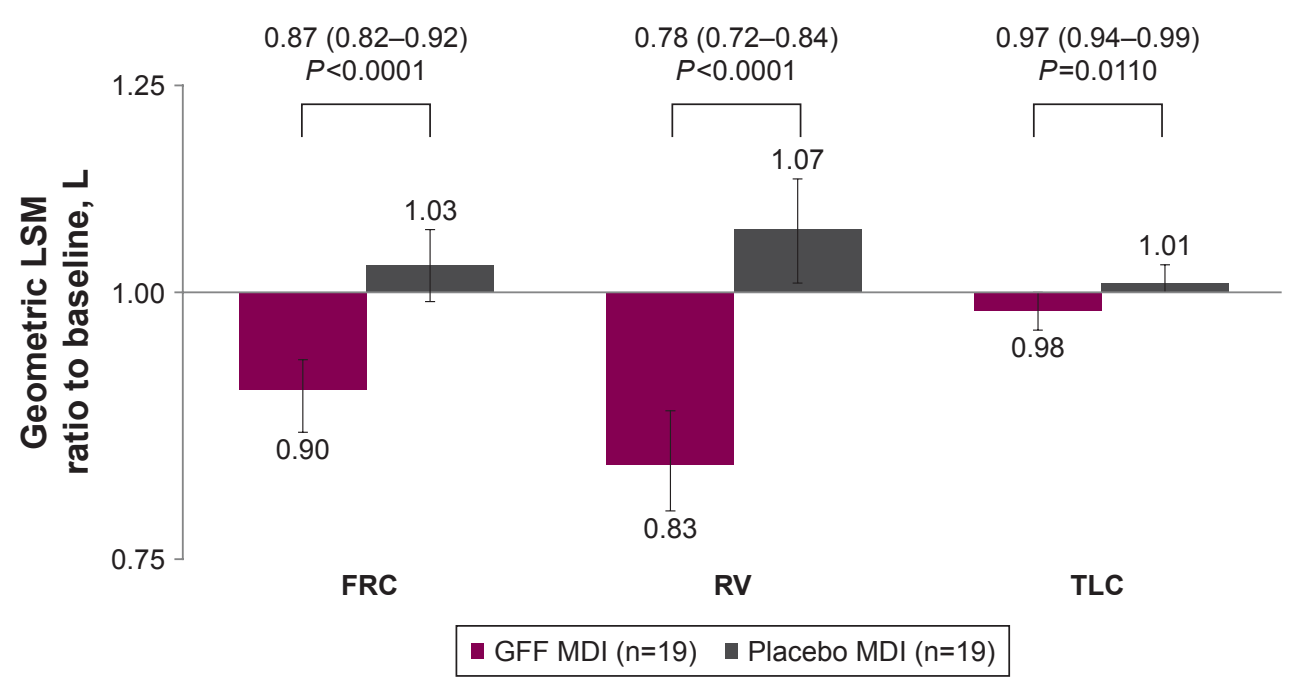

Figure 7 Body plethysmography endpoints on Day I5: ratio to baseline in post-dose FRC, RV, and TLC (intent-to-treat population).

Note: Error bars and parentheses represent $95 \% \mathrm{Cls}$.

Abbreviations: FRC, functional residual capacity; GFF, glycopyrrolate/formoterol fumarate; LSM, least squares mean; MDI, metered dose inhaler; RV, residual volume; TLC, total lung capacity.

lung. In other FRI studies of bronchodilators in patients with severe COPD, single doses of the short-acting bronchodilators ipratropium bromide $(80 \mu \mathrm{g})$ and salbutamol $(400 \mu \mathrm{g})$ - both double the standard prescribed dose for the treatment of COPD and administered with a valved spacer - showed a $\sim 32 \%$ increase in distal airway volume and a $\sim 58 \%$ decrease in distal airway resistance, with each treatment compared to pre-dose. ${ }^{2}$ In addition, single-dose beclomethasone/formoterol 200/12 $\mu \mathrm{g}$ MDI and budesonide/formoterol 160/4.5 $\mu \mathrm{g}$ dry powder inhaler significantly increased airway volume by around $10 \%$ (siVaw vs baseline and iVaw vs placebo) and reduced airway resistance by around 35\% (siRaw vs baseline) and 16\% (iRaw difference from placebo), respectively, in patients with COPD. ${ }^{1,3}$
The homogeneous bronchodilation observed in this study supports the findings from a gamma scintigraphy study in healthy subjects, ${ }^{24}$ which found that GFF MDI was deposited in all regions of the lungs. FRI is also able to provide an image-based, numeric measure of drug deposition in the lungs ${ }^{17}$ and, using patient-specific inhalation profiles, estimated that approximately $48 \%$ of the total delivered dose of glycopyrronium and formoterol fumarate from GFF MDI could be deposited in the lungs. These FRI-based deposition results were higher than the gamma scintigraphy study (a 2D-imaging technique using ${ }^{99 \mathrm{~m}} \mathrm{Tc}$ radiolabels) that reported a lung deposition of $38 \%$ of the emitted dose of GFF MDI. ${ }^{24}$ In this study of patients with COPD, the simulation provided information about total drug deposition characteristics of

Table 2 Summary of AEs (safety population)

\begin{tabular}{|c|c|c|c|}
\hline Parameters & $\begin{array}{l}\text { GFF MDI } \\
(n=20)\end{array}$ & $\begin{array}{l}\text { Placebo MDI } \\
(n=19)\end{array}$ & $\begin{array}{l}\text { Total } \\
(\mathbf{N}=\mathbf{2 0})\end{array}$ \\
\hline At least one TEAE & $12(60.0)[19]$ & $8(42.1)[14]$ & I5 (75.0) [33] \\
\hline TEAEs related to study drug ${ }^{a}$ & $6(30.0)[10]$ & $5(26.3)[6]$ & $10(50.0)[16]$ \\
\hline Serious TEAEs & $\mathrm{I}(5.0)[\mathrm{I}]^{\mathrm{b}}$ & $\mathrm{I}(5.3)[1]^{\mathrm{c}}$ & $2(10.0)[2]$ \\
\hline Serious TEAEs related to study druga & $\mathrm{I}(5.0)[\mathrm{I}]^{\mathrm{b}}$ & $\mathrm{I}(5.3)[1]^{\mathrm{c}}$ & $2(10.0)[2]$ \\
\hline TEAEs leading to early discontinuation & $\mathrm{I}(5.0)[\mathrm{I}]^{\mathrm{d}}$ & 0 & $\mathrm{I}(5.0)[\mathrm{I}]^{\mathrm{d}}$ \\
\hline Deaths - all causes & 0 & 0 & 0 \\
\hline \multicolumn{4}{|c|}{ AEs observed in $\geq 2$ patients in any treatment period (preferred term) } \\
\hline Exertional dyspnea & 0 & $3(15.8)[3]$ & $3(15.0)[3]$ \\
\hline Dyspnea & $2(10.0)[2]$ & 0 & $2(10.0)[2]$ \\
\hline Dizziness & $2(10.0)[2]$ & 0 & $2(10.0)[2]$ \\
\hline Headache & $2(10.0)[2]$ & $\mathrm{I}(5.3)[\mathrm{I}]$ & $2(10.0)[3]$ \\
\hline Tremor & $2(10.0)[2]$ & $\mathrm{I}(5.3)[\mathrm{I}]$ & $2(10.0)[3]$ \\
\hline Respiratory tract infection & $2(10.0)[2]$ & 0 & $2(10.0)[2]$ \\
\hline
\end{tabular}

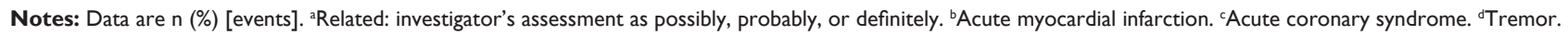
Abbreviations: AE, adverse event; GFF, glycopyrrolate/formoterol fumarate; MDI, metered dose inhaler; TEAE, treatment-emergent adverse event. 
GFF MDI and aligned them with the regional airway volume and resistance characteristics observed.

Given the short TP, the minimal change in FRI-measured iVlobe in patients following GFF MDI or placebo MDI treatment was not unexpected and reflected the consistency of the FRI measurement.

Although HRCT is considered minimally invasive, the scan protocols kept the radiation dose lower than that of a traditional chest computed tomography (CT) scan (1-2 mSv vs $7 \mathrm{mSv}$ ). Despite the relatively small population, the study was well powered, and the size is not unusual for a study of this type. ${ }^{1,2,5}$ The 14-day study duration ensured that steadystate pharmacokinetics were achieved for glycopyrrolate and formoterol. ${ }^{11,13}$

GFF MDI treatment was associated with statistically significant and clinically meaningful improvements in spirometry-measured post-dose $\mathrm{FEV}_{1}$, IC, and FVC vs placebo MDI. The improvements in IC were consistent with two 4-week studies of GFF MDI in patients with moderate-tovery severe COPD (248-381 $\mathrm{mL}$ peak change from baseline in IC) and a 7-day study of higher doses of GFF MDI (GFF MDI 72/9.6 $\mu \mathrm{g}$ and 36/9.6 $\mu \mathrm{g}$; 265-293 mL peak change from baseline in IC). ${ }^{13,14}$ GFF MDI treatment amounted to a decrease of approximately half a liter in FRC and RV vs placebo MDI (13\% and $22 \%$, respectively), which is consistent with the reduction in FRI airway resistance observed and implies a reduction in air trapping and hyperinflation. These results are similar to those reported for two placebocontrolled LAMA/LABA studies of aclidinium/formoterol (400/12 $\mu \mathrm{g} ; 4$ weeks) and tiotropium/olodaterol $(2.5 / 5 \mu \mathrm{g}$ and $5 / 5 \mu \mathrm{g} ; 6$ weeks), which reported change from baseline improvements vs placebo in an FRC of 366-535 mL and in $\mathrm{RV}$ in the region of $465-660 \mathrm{~mL} .^{25,26}$

The safety findings were consistent with the known safety profile of GFF MDI, and the AEs were expected within a population of patients with moderate-to-severe COPD.

GFF MDI is formulated using co-suspension delivery technology that has demonstrated uniform delivery throughout the whole lung in vivo ${ }^{24}$ and consistent dose delivery in the presence of simulated patient-handling errors in vitro. ${ }^{27}$ This study, which evaluated the physiologic effects of GFF MDI drug delivery, evidenced bronchodilator distribution throughout the lung, resulting in improvements in airway volume, airway resistance, bronchodilation, and hyperinflation.

\section{Conclusion}

In this FRI study of lung function in patients with moderateto-severe COPD, the dual bronchodilator GFF MDI 18/9.6 $\mu \mathrm{g}$ demonstrated significant, clinically meaningful benefits on airway volume and resistance associated with drug deposition throughout the whole lung. Using FRI has allowed for further regional characterization of the bronchodilator effects of GFF MDI in patients with COPD, alongside more traditional techniques, which has further demonstrated the physiological effects behind the clinically meaningful improvements in $\mathrm{FEV}_{1}$ and lung hyperinflation parameters.

\section{Acknowledgments}

The authors thank all the patients, their families, and the team of investigators, research nurses, and operations staff involved in these studies. The authors also thank Sarvajna Dwivedi (Pearl - a member of the AstraZeneca Group) for his valuable contributions. Medical writing support, under the direction of the authors, was provided by Siobhán Hoy $\mathrm{BSc}$ of $\mathrm{CMC}$ Connect, a division of Complete Medical Communications Ltd, Glasgow, UK, funded by AstraZeneca, Cambridge, UK in accordance with Good Publication Practice (GPP3) guidelines. ${ }^{28}$ This study was supported by Pearl - a member of the AstraZeneca Group. The funder of the study was involved in the study design, data analysis, data interpretation, and writing of the report. All authors had full access to all the data in the study and the corresponding author had the final responsibility for the decision to submit for publication. No restrictions were placed on authors regarding the statements made in the manuscript. Part of this work was presented at the European Respiratory Society International Congress, 2017, Milan, Italy (De Backer W, De Backer J, Vos W, et al. Functional respiratory imaging [FRI] and lung function assessment of glycopyrronium/formoterol fumarate dihydrate fixed-dose combination delivered using novel Co-Suspension Delivery Technology [GFF MDI] in COPD [abstract]. Eur Respir J. 2017;50[Suppl 61]:OA4404) and at the British Thoracic Society Winter Meeting, 2017, London, UK (De Backer W, De Backer J, Vos W, et al. Functional respiratory imaging [FRI] and lung function assessment of glycopyrronium/formoterol fumarate dihydrate fixed-dose combination delivered using innovative co-suspension delivery technology [GFF MDI] in COPD [abstract]. Thorax. 2017;72:A186-A188).

\section{Author contributions}

The study concept and design was constructed by WDB, JDB, CVH, BH, SS, and CR. The acquisition, analysis, or interpretation of the data was performed by WDB, JDB, IV, CVH, WV, JC, BH, MJ, CR, and UJM. Study initiation/ investigator meeting at site was done by SS. The statistical analysis was performed by $\mathrm{WV}, \mathrm{CVH}, \mathrm{BH}, \mathrm{MJ}$, and $\mathrm{CR}$. The drafting of the manuscript was performed by WDB, JDB, IV, 
CVH, WV, JC, BH, SS, MJ, CR, and UJM. All authors contributed toward data analysis, drafting and revising the paper and agree to be accountable for all aspects of the work.

\section{Disclosure}

$\mathrm{WDB}, \mathrm{JC}$, and $\mathrm{BH}$ have no real or perceived conflicts of interest that relate to this manuscript. WDB's department has received grants from AstraZeneca, Chiesi, and GlaxoSmithKline. JDB is the Chief Executive Officer and founder of FLUIDDA and holds shares in the company. WV is an employee of FLUIDDA and holds shares in the company. IV and CVH are employees of FLUIDDA. SS, MJ, and UJM are employees of AstraZeneca. CR is the Chief Executive Officer of Pearl - a member of the AstraZeneca Group and an employee of AstraZeneca. All Pearl and AstraZeneca employees own AstraZeneca stocks. The authors report no other conflicts of interest in this work.

\section{References}

1. De Backer LA, Vos W, De Backer J, van Holsbeke C, Vinchurkar S, De Backer W. The acute effect of budesonide/formoterol in COPD: a multi-slice computed tomography and lung function study. Eur Respir J. 2012;40(2):298-305.

2. De Backer LA, Vos WG, Salgado R, et al. Functional imaging using computer methods to compare the effect of salbutamol and ipratropium bromide in patient-specific airway models of COPD. Int $J$ Chron Obstruct Pulmon Dis. 2011;6:637-646.

3. De Backer J, Vos W, Vinchurkar S, et al. The effects of extrafine beclometasone/formoterol (BDP/F) on lung function, dyspnea, hyperinflation, and airway geometry in COPD patients: novel insight using functional respiratory imaging. J Aerosol Med Pulm Drug Deliv. 2015; 28(2):88-99.

4. De Backer J, Vos W, van Holsbeke C, et al. Effect of high-dose $\mathrm{N}$-acetylcysteine on airway geometry, inflammation, and oxidative stress in COPD patients. Int J Chron Obstruct Pulmon Dis. 2013;8:569-579.

5. De Backer J, van Holsbeke C, Vos W, et al. Assessment of lung deposition and analysis of the effect of fluticasone/salmeterol hydrofluoroalkane (HFA) pressurized metered dose inhaler (pMDI) in stable persistent asthma patients using functional respiratory imaging. Expert Rev Respir Med. 2016;10(8):927-933.

6. De Backer L, Vos W, Dieriks B, et al. The effects of long-term noninvasive ventilation in hypercapnic COPD patients: a randomized controlled pilot study. Int J Chron Obstruct Pulmon Dis. 2011;6:615-624.

7. De Backer W, Vos W, van Holsbeke C, et al. The effect of roflumilast in addition to LABA/LAMA/ICS treatment in COPD patients. Eur Respir J. 2014;44(2):527-529.

8. Vos W, Hajian B, De Backer J, et al. Functional respiratory imaging to assess the interaction between systemic roflumilast and inhaled ICS/ LABA/LAMA. Int J Chron Obstruct Pulmon Dis. 2016;11:263-271.

9. Ides K, Vos W, De Backer L, et al. Acute effects of intrapulmonary percussive ventilation in COPD patients assessed by using conventional outcome parameters and a novel computational fluid dynamics technique. Int J Chron Obstruct Pulmon Dis. 2012;7:667-671.

10. Janssens A, Vos W, van Holsbeke C, et al. Estimation of post-operative forced expiratory volume by functional respiratory imaging. Eur Respir J. 2015;45(2):544-546.
11. AstraZeneca Pharmaceuticals LP. Information SP; 2017. Available from: http://www.azpicentral.com/symbicort/symbicort.pdf. Accessed October 6, 2017.

12. Martinez FJ, Rabe KF, Ferguson GT, et al. Efficacy and safety of glycopyrrolate/formoterol metered dose inhaler formulated using cosuspension delivery technology in patients with COPD. Chest. 2017; 151(2):340-357.

13. Hanania NA, Tashkin DP, Kerwin EM, et al. Long-term safety and efficacy of glycopyrrolate/formoterol metered dose inhaler using novel Co-Suspension ${ }^{\mathrm{TM}}$ Delivery Technology in patients with chronic obstructive pulmonary disease. Respir Med. 2017;126:105-115.

14. Reisner C, Gottschlich G, Fakih F, et al. 24-h bronchodilation and inspiratory capacity improvements with glycopyrrolate/formoterol fumarate via co-suspension delivery technology in COPD. Respir Res. 2017; 18(1):157.

15. Celli BR, Macnee W; ATS/ERS Task Force. Standards for the diagnosis and treatment of patients with COPD: a summary of the ATS/ERS position paper. Eur Respir J. 2004;23(6):932-946.

16. Hajian B, De Backer J, Vos W, van Holsbeke C, Clukers J, De Backer W. Functional respiratory imaging (FRI) for optimizing therapy development and patient care. Expert Rev Respir Med. 2016;10(2):193-206.

17. De Backer JW, Vos WG, Vinchurkar SC, et al. Validation of computational fluid dynamics in CT-based airway models with SPECT/CT. Radiology. 2010;257(3):854-862.

18. Miller MR, Hankinson J, Brusasco V, et al. Standardisation of spirometry. Eur Respir J. 2005;26(2):319-338.

19. Cazzola M, Macnee W, Martinez FJ, et al. Outcomes for COPD pharmacological trials: from lung function to biomarkers. Eur Respir J. 2008; 31(2):416-469.

20. O'Donnell DE, Lam M, Webb KA. Spirometric correlates of improvement in exercise performance after anticholinergic therapy in chronic obstructive pulmonary disease. Am J Respir Crit Care Med. 1999; 160(2):542-549.

21. O’Donnell DE, Flüge T, Gerken F, et al. Effects of tiotropium on lung hyperinflation, dyspnoea and exercise tolerance in COPD. Eur Respir J. 2004;23(6):832-840.

22. O’Donnell DE, Voduc N, Fitzpatrick M, Webb KA. Effect of salmeterol on the ventilatory response to exercise in chronic obstructive pulmonary disease. Eur Respir J. 2004;24(1):86-94.

23. O'Donnell DE. Impacting patient-centred outcomes in COPD: breathlessness and exercise tolerance. European Respiratory Review. 2006; 15(99):37-41.

24. Taylor G, Warren S, Dwivedi S, et al. Gamma scintigraphic pulmonary deposition study of glycopyrronium/formoterol metered dose inhaler formulated using co-suspension delivery technology. Eur J Pharm Sci. 2018; 111:450-457.

25. Watz H, Troosters T, Beeh KM, et al. ACTIVATE: the effect of aclidinium/formoterol on hyperinflation, exercise capacity, and physical activity in patients with COPD. Int J Chron Obstruct Pulmon Dis. 2017; 12:2545-2558.

26. Beeh KM, Westerman J, Kirsten AM, et al. The 24-h lung-function profile of once-daily tiotropium and olodaterol fixed-dose combination in chronic obstructive pulmonary disease. Pulm Pharmacol Ther. 2015; 32:53-59.

27. Doty A, Schroeder J, Vang K, et al. Drug delivery from an innovative LAMA/LABA co-suspension delivery technology fixed-dose combination MDI: evidence of consistency, robustness, and reliability. AAPS PharmSciTech. 2018;19(2):837-844.

28. Battisti WP, Wager E, Baltzer L, et al. Good publication practice for communicating company-sponsored medical research: GPP3. Ann Intern Med. 2015;163(6):461-464. 


\section{Supplementary materials Methods}

Patients were excluded if they had a current diagnosis of asthma or other respiratory disorders (where the severity of the disorder would impact the conduct of the study in the opinion of the Investigator); had been hospitalized due to poorly controlled COPD within 3 months prior to screening or during the run-in period; or had been treated with oral corticosteroids or antibiotics due to poorly controlled COPD within 6 weeks prior to screening or during the run-in period. Patients taking oral steroids (equivalent to prednisone $5 \mathrm{mg}$ per day or $10 \mathrm{mg}$ every other day) for at least 3 months prior to screening were eligible for enrollment, provided the dose remained stable during the run-in period. Patients who had lung volume reduction surgery within 1 year prior to screening, required long-term oxygen therapy for more than 12 hours a day, and patients who had a recent change in smoking status or initiated a smoking cessation program (within 6 weeks prior to screening or within the run-in period) were also excluded.

The pre-dose high-resolution computed tomography (HRCT) scans were performed at total lung capacity (TLC) and functional residual capacity (FRC) on Day 1. On Day 15, post-dose HRCT scans were performed at TLC using a GE VCT LightSpeed ${ }^{\mathrm{TM}}$ 64-slice scanner (General Electric Company, Boston, MA, USA). These HRCT images were imported into Mimics ${ }^{\circledR}$, an FDA-approved medical image processing software package (Materialise, Leuven, Belgium), and converted into subject-specific, 3D computer models of the airways and lungs. Airway volume inside the airway tree (image-based airway volume [iVaw]) was evaluated at FRC and TLC levels down to bronchi with a diameter of around 1-2 mm. A typical airway model includes 5-10 generations, mainly depending on the disease state of the individual subject. Evaluating lobe volume at FRC and TLC allowed for determination of lobar expansion and consequently internal mass flow distribution, which were used as boundary conditions for the computational fluid dynamics.

The airway trees were divided into discrete tetrahedral elements in the meshing software package TGrid ${ }^{\mathrm{TM}} 14.0$ (Ansys, Inc., Canonsburg, PA, USA). Flow and particle properties were obtained throughout the entire flow domain using Ansys Fluent 14.0 (Ansys, Inc.).

Airway resistance (image-based airway resistance [iRaw]) was defined as the total pressure drop over the airway divided by the flow rate through that airway. Specific imagebased airway resistance (siRaw) was derived by multiplying iRaw for each lobe by the corresponding lobe volume (imagebased lobe volume [iVlobe]). Specific image-based airway volume (siVaw) was derived by dividing iVaw for each lobe by the iVlobe.

Table SI Prior COPD-related medications (safety/intent-to-treat population)

\begin{tabular}{ll}
\hline Medications & $\begin{array}{c}\text { Total } \\
(\mathbf{N}=\mathbf{2 0})\end{array}$ \\
\hline Any prior COPD medication & $19(95.0)$ \\
$\quad$ Tiotropium & $10(50.0)$ \\
Fluticasone & $7(35.0)$ \\
Fluticasone/salmeterol & $7(35.0)$ \\
Ipratropium/fenoterol & $4(20.0)$ \\
Salbutamol & $4(20.0)$ \\
Beclometasone & $3(15.0)$ \\
Glycopyrrolate/indacaterol & $3(15.0)$ \\
Beclometasone/formoterol fumarate & $2(10.0)$ \\
Umeclidinium/vilanterol & $2(10.0)$ \\
Budesonide & $1(5.0)$ \\
Budesonide/formoterol fumarate & $1(5.0)$ \\
Glycopyrrolate & $1(5.0)$ \\
Indacaterol & I (5.0) \\
Roflumilast & I (5.0) \\
\hline
\end{tabular}

Notes: Data are $\mathrm{n}(\%)$. Overall, 19 patients received at least one COPD-related medication prior to study entry. Patients may have received more than one COPD-related medication. 

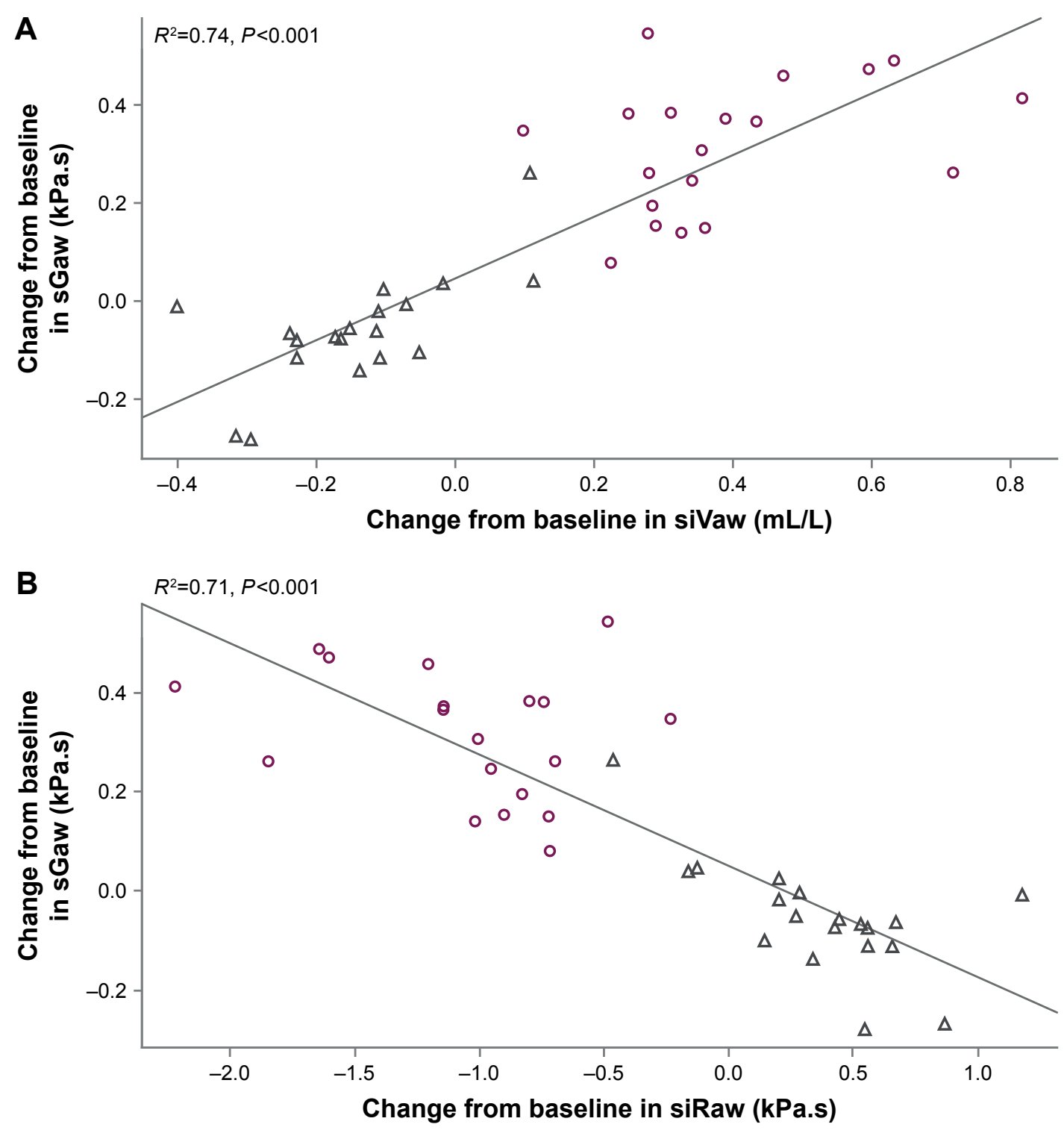

○ GFF MDI 18/9.6 $\mu \mathrm{g}(\mathrm{n}=19) \quad \Delta$ Placebo MDI $(\mathrm{n}=19)$

Figure SI Scatter plot comparison of change from baseline in siVaw (A) and siRaw (B) with change from baseline in sGaw at Day I5.

Abbreviations: GFF, glycopyrrolate/formoterol fumarate; MDI, metered dose inhaler; sGaw, specific airway conductance; siRaw, specific image-based airway resistance; siVaw, specific image-based airway volume.

\section{Publish your work in this journal}

The International Journal of COPD is an international, peer-reviewed journal of therapeutics and pharmacology focusing on concise rapid reporting of clinical studies and reviews in COPD. Special focus is given to the pathophysiological processes underlying the disease, intervention programs, patient focused education, and self management protocols.

\section{Dovepress}

This journal is indexed on PubMed Central, MedLine and CAS. The manuscript management system is completely online and includes a very quick and fair peer-review system, which is all easy to use. Visit $\mathrm{http} / / / \mathrm{www}$.dovepress.com/testimonials.php to read real quotes from published authors. 